\title{
An antisocial alchemy: Psychopathic traits as a moderator of the different forms and functions of aggression in delinquency and conduct disorder among youth
}

\author{
Matt DeLisi $^{\text {a, *, Pedro Pechorro }}{ }^{\mathrm{b}}$, Rui Abrunhosa Gonçalves ${ }^{\mathrm{b}}$, João Marôco ${ }^{\mathrm{c}}$ \\ ${ }^{a}$ Department of Sociology and Criminal Justice, Iowa State Uniersity, 203A East Hall, Ames, IA 50011-1070, USA \\ ${ }^{\mathrm{b}}$ School of Psychology, University of Minho, Campus de Gualtar, 4710-057 Braga, Portugal \\ ${ }^{\mathrm{c}}$ William James Centre for Research, ISPA-Instituto Universitário, 1149-041 Lisboa, Portugal
}

\section{A R T I C L E I N F O}

\section{Keywords:}

Aggression

Delinquency

Moderation

Psychopathic traits

Youth

Conduct disorder

\begin{abstract}
A B S T R A C T
The aim of the present study is to examine the possible role of psychopathic traits as a moderator of the aggression-antisociality/delinquency link. Our sample was composed of 567 youth $(M=15.91$ years, $S D=0.99$ years, age range $=14-18$ years) from Portugal. Results indicated that psychopathic features significantly moderate four different forms and functions of aggression - proactive overt, proactive relational, reactive overt, and reactive relational - when predicting delinquency. However, psychopathic traits only significantly moderate proactive relational aggression when predicting Conduct Disorder. Psychopathic traits and aggression constitute an antisocial alchemy for antisocial behavior but more research is needed about moderation effects therein particularly among clinical and justice system involved samples of youth to inform behavioral interventions.
\end{abstract}

\section{Introduction}

Aggression and psychopathy are two of the most fundamental and pernicious risk factors for delinquency and related conduct problems (Anderson \& Bushman, 2002; Card \& Little, 2006; DeLisi, 2016; Geerlings, Asscher, Stams, \& Assink, 2020; Lorber, 2004; Raine et al., 2006). ${ }^{1}$ Defined as the motivation to inflict harm on a victim who seeks to avoid that harm (Anderson \& Bushman, 2002), aggression is a multifaceted construct that is conceptualized into different forms and functions (Crick \& Dodge, 1996; Dodge \& Coie, 1987). These forms and functions exist along two dimensions. The first dimension encompasses whether the aggression is premeditated, planned, calculated, and involves an instrumental goal (proactive) or whether the aggression is unplanned, impulsive, and in response to some real or perceived provocation (reactive). The second dimension relates to its directness. Relational or indirect aggression is usually verbal, covert, and includes behaviors meant to damage another person in terms of their social functioning (e. g., gossiping and ostracism). Overt or direct aggression is typically physical and includes direct contact behaviors involving the use of force as seen in assault, battery, sexual assault, and homicide.

A large corpus of research indicates that aggression in its various forms and functions is associated with antisocial behavior and related problems (e.g.,Barker, Tremblay, Nagin, Vitaro, \& Lacourse, 2006; Card \& Little, 2006; Marsee \& Frick, 2007; Polman, de Castro, Koops, van Boxtel, \& Merk, 2007; Raine et al., 2006; Vitaro, Gendreau, Tremblay, \& Oligny, 1998) and aggression constitutes a major fiscal burden due to the health, mental health, school, and justice system costs associated with responding to it (Foster et al., 2005). Similarly, psychopathy, which is commonly characterized as a personality disorder characterized by self-regulation problems, a manipulative, exploitative, and selfish interpersonal style, and reduced conscience illustrated by reduced empathy, remorse, or guilt is consistently associated with delinquency and conduct problems among youth (American Psychiatric Association, 2013, p. 765; DeLisi, 2016; Frick, Cornell, Barry, Bodin, \& Dane, 2003; Geerlings et al., 2020; Hare, 1999; Lee \& Kim, 2020). Indeed, psychopathy and aggression are some of the basic ingredients of antisocial

\footnotetext{
* Corresponding author.

E-mail addresses: delisi@iastate.edu (M. DeLisi), rabrunhosa@psi.uminho.pt (R.A. Gonçalves), jpmaroco@ispa.pt (J. Marôco).

1 We employ "psychopathy" when discussing the broader concept as it relates to conduct problems and antisocial behavior. We employ the language "psychopathic

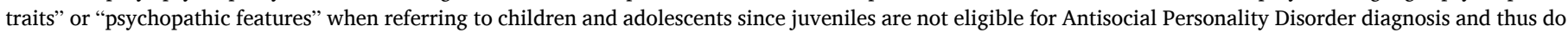

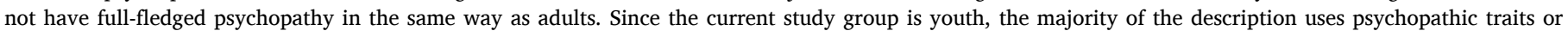
features.
} 
behavior (DeLisi \& Vaughn, 2015). ${ }^{2}$

Although aggression and psychopathy are formidable risk factors for delinquency on their own, it is likely that as a personality tendency, psychopathy moderates the association between aggression and antisocial outcomes. This is particularly the case when considering the various forms and functions of aggression. For instance, proactive forms of aggression are likely appealing to youth with greater psychopathic features for a variety of reasons due to the specific, externally reinforcing features of the disorder including the instrumental nature of criminal offending that is disproportionately seen in psychopathy, the parasitic lifestyle orientation that facilitates goal-specific offending, and the complete indifference to victims affected by their aggression. Similarly, reactive aggression is likely among youth with psychopathic features due to the impulsive conduct and global impairments in selfcontrol that are characteristic of the disorder. Due to the manipulative and exploitative interpersonal style in psychopathy, relational aggression also has usefulness as a means to damage another person for one's gain. To illustrate, Cima and Raine (2009) found specific features of psychopathy were significantly correlated with reactive and proactive aggression especially fearlessness, Machiavellianism, impulsive nonconformity, alienation, and carefree nonplanfulness in a sample of male prisoners. Other researchers similarly found that specific psychopathic features correlated with distinct forms of aggression including reactive and proactive overt and reactive and proactive relational (e.g., Lau \& Marsee, 2013; Marsee, Silverthorn, \& Frick, 2005).

Despite the potential moderation effects seen for the psychopathyaggression-delinquency relationship, research has underexplored this association perhaps because research on the constructs spans multiple academic disciplines (Farrington, 2009). To be sure, a variety of studies reported evidence that psychopathy moderates the association between peer influence and effects (Kerr, Van Zalk, \& Stattin, 2012), verbal ability (Muñoz, Frick, Kimonis, \& Aucoin, 2008), parental affect (Yeh, Chen, Raine, Baker, \& Jacobson, 2011), and treatment interventions (Manders, Deković, Asscher, van der Laan, \& Prins, 2013), and delinquency. Moreover, researchers found that gender moderates the linkages between psychopathic features and delinquency (Orue, Calvete, \& Gamez-Guadix, 2016). However, whether psychopathy moderates the effects of the various forms and functions of aggression on delinquent outcomes is less clear. We hypothesize that psychopathic traits moderates the connection between various forms of aggression to delinquency and related conduct problems. Specifically, we hypothesize that psychopathic features as measured by the DD Psychopathy factor moderates proactive overt, proactive relational, reactive overt, and reactive relational aggression in predicting delinquency and conduct disorder outcomes.

\section{Method}

\subsection{Participants}

Our sample was composed of 567 youth $(M=15.91$ years, $S D=0.99$ years, age range $=14-18$ years), namely 256 females $(M=15.80$ years, $S D=1.02$, range $=14-18)$ and 311 males $(M=15.99$ years, $S D=0.96$, range $=14-18)$. No significant differences between genders were detected in terms of age $(F=3.38, p=0.06)$, socioeconomic status ( $U=$ $38,318.5, p=0.41)$, or education $(F=0.63, p=0.42)$. The majority of the participants were Portuguese nationals $(88.4 \%)$ with approximately nine years of education on average $(M=8.95, S D=0.94)$.

\footnotetext{
2 There is scholarly disagreement about psychopathy vis-à-vis Antisocial Personality Disorder and its broader classification as a personality construct (see, Hare, 1996; Hare, Hart, \& Harpur, 1991; Ogloff, 2006; Shipley \& Arrigo, 2001; Yoon, Eher, \& Mokros, 2021).
}

\subsection{Measures}

\subsubsection{Predictor}

Peer Conflict Scale-20 (PCS-20; Marsee et al., 2011). This is brief 20item self-report four-dimensional measure that taps the different forms and functions of aggression. The PCS-20 has five proactive overt items (PO; e.g., "I start fights to get what I want"), five proactive relational items (PR; e.g., "I gossip about others to become popular"), five reactive overt items (RO; e.g., "When someone hurts me, I end up getting into a fight"), and five reactive relational items (RR; e.g., "If others make me mad, I tell their secrets"). Items are rated on a 4-point Likert scale (ranging from $0=$ Not at all true, to $3=$ Definitely true). The respective items were summated to obtain the factors scores. Higher scores indicate higher levels of aggression. The PCS-20 was validated in Portugal among the youth forensic population (Pechorro et al., 2020; Pechorro, Russell, Ayala-Nunes, Gonçalves, \& Nunes, 2018). The internal consistency (Cronbach's $\alpha$ ) for the current study was excellent for all forms and functions of aggression: PO $\alpha=0.90, \mathrm{PR} \alpha=0.82, \mathrm{RO} \alpha=0.92, \mathrm{RR} \alpha=$ 0.84 , and PCS-20 total $\alpha=0.94$.

\subsubsection{Moderator}

Psychopathy - Dirty Dozen (DD; Jonason \& Webster, 2010). This is a brief 12-item tridimensional measure of the Dark Triad construct of personality composed of psychopathy, Machiavellianism, and narcissism although we used only the psychopathy factor that includes four items (e.g., I tend to be unconcerned with the morality of my actions; I tend to be callous or insensitive) for the current study. Items on the current study are rated on a 5-point ordinal Likert scale (ranging from 1 $=$ Strongly Disagree, to $5=$ Strongly Agree). The respective items were summated to obtain the factors score of the psychopathy factor. Higher scores on the psychopathy factor indicate higher levels of psychopathic features. The version of the DD is validated in Portugal among the youth population (Pechorro, Jonason, Raposo, \& Maroco, 2019) and the internal consistency for the current study was excellent (Cronbach's $\alpha=$ 0.94).

\subsubsection{Outcomes}

Add Health Self-Report Delinquency (AHSRD; Pechorro, DeLisi, Gonçalves, Quintas, \& Palma, 2019a; Pechorro, Moreira, Basto-Pereira, Oliveira, \& Ray, 2019b). This is a 17-item self-report measure of juvenile delinquency originally developed for the National Longitudinal Study of Adolescent Health (Add Health). The AHSRD taps violent and non-violent criminal behaviors occurring during the last 12 months before the assessment (e.g., "Take something from a store without paying for it"; "Get into a serious physical fight?"). Items are rated on a 4-point Likert scale (ranging from $0=$ None, to $3=$ Five or more times). Items were summated to obtain a total score. Higher scores indicate higher levels of self-reported criminality. The AHSRD was validated in Portugal among the youth population (Pechorro, DeLisi, et al., 2019a; Pechorro, Moreira, et al., 2019b) and the internal consistency for the current study was excellent (Cronbach's $\alpha=0.93$ ).

Conduct Disorder Screener (CDS; Lewinsohn, Rohde, \& Farrington, 2000). This is a brief self-report screener created to identify adolescents with conduct disorder. The CDS consists of six items representative of a diagnosis of Conduct Disorder (e.g., "I broke rules at school"; "I got in trouble for lying or stealing"). Items are rated on a 4-point ordinal Likert scale (ranging from $1=$ Rarely or none of the time, to $4=$ Most or all of the time). Items were summated to obtain a total score. Higher scores indicate higher levels of conduct disorder. The CDS was validated in Portugal among the youth population (Palma, Pechorro, Jesus, \& Nunes, 2021) and the internal consistency for the current study was excellent (Cronbach's $\alpha=0.92$ ).

\subsection{Procedures}

The Ministry of Education (ME) of Portugal provided authorization 
to assess the participants of the present study. These participants came from five schools in southern regions of Portugal, including the greater Lisbon area, Alentejo and Algarve regions. This was a convenience sample not originally intended to be representative of the national student population. However, the sample purposely contained youth from different urban (e.g., Lisbon), and rural backgrounds (Alentejo and Algarve regions) to make it more diverse. This sample did not include potential participants with co-morbid disorders (e.g., developmental disorders, serious mental illness) because in Portugal youth needing special resources attend separate classes with individualized curricula or if they are not to be able to reach their individual educational goals they are diverted to special needs schools. Written parental authorization was previously obtained, and then the potential participants were themselves informed about the aims of our investigation and asked to collaborate voluntarily. Due to various motives some youth were excluded (e.g., those who could not read/understand Portuguese, those who were reluctant to participate, those who were 13 or younger to make ensure the reading level was generally appropriate to the item content of the measures used, those who were 19 years old or older because they are considered young adults). The rate of participation was $89 \%$. No form of compensation was given to the participants or their parents, including monetary compensation. The measures and sociodemographic questionnaire included in the present study were administered in small groups of participants. The measures used in the present study were selected because they were considered appropriate in terms of our research aims, they are validated in Portugal, and are psychometrically robust.

\subsection{Data analysis}

The EQS. 6.4 software (Bentler \& Wu, 2018) was used to estimate path analysis models. Pearson correlations were considered high if $>0.50$, low if below $<0.20$, and moderate if in between (Ferguson, 2009). To compare groups, ANOVAs and Mann-Whitney's $U$ test were used. Alpha coefficient was considered adequate if $>0.70$, and good if $>0.80$ (Maroco, 2014). Path analysis using constructs score were used to overcome sample size limitations and estimation errors. When the reliability of constructs is high, the underestimation of beta coefficients using path analysis is irrelevant (Maroco, 2014). We tested four fully saturated models with standardized variables. In Model 1, Proactive Overt aggression, psychopathic traits, and the interaction between both predicted delinquency and conduct disorder. In Model 2, Proactive Relational aggression, psychopathy, and the interaction between both predicted delinquency and conduct disorder. In Model 3, Reactive Overt aggression, psychopathic traits, and the interaction between both predicted delinquency and conduct disorder. In Model 4, Reactive Relational aggression, psychopathic traits, and the interaction between both predicted delinquency and conduct disorder. Our models did not include the potential influence of covariates (e.g., individual, family and community variables) because the participants selection criterion aimed at homogenous participants (e.g., in terms of age, reading ability) and because this is a first approach to the investigation psychopathy-forms and functions of aggression-delinquency/CD relationship research theme. Maximum Likelihood (ML) estimation methods with covariance matrices were used, which are considered robust for non-severe violations of the normality (absolute skewness and kurtosis values below 3 and 10, respectively; Blunch, 2016).

\section{Results}

Table 1 displays the Pearson correlation matrix and descriptive statistics of the measures used. DD Psychopathy had moderate to large correlations with Proactive Overt aggression $(r=0.71, p \leq 0.001)$, Proactive Relational aggression ( $r=0.44, p \leq 0.001)$, Reactive Overt aggression $(r=0.64, p \leq 0.001)$, and Reactive Relational aggression $(r$ $=0.32, p \leq 0.001$ ).

Fig. 1 displays the first model. In this model Proactive Overt aggression $(\beta=0.28, p<0.001$ for delinquency and $\beta=0.37, p<0.001$ for $\mathrm{CD}$ ), psychopathic features ( $\beta=0.33, p<0.001$ for delinquency and $\beta=0.49, p<0.001$ for $\mathrm{CD}$ ), and the interaction between both $(\beta=0.33$, $p<0.001$ for delinquency and $\beta=0.02, n s$ for $\mathrm{CD}$ ) were significantly associated with the outcomes, with the exception of the interaction regarding $\mathrm{CD}$ which was non-significant.

Next, Fig. 2 shows model 2. In this model Proactive Relational aggression $(\beta=0.17, p<0.001$ for delinquency and $\beta=0.16, p<0.01$ for $\mathrm{CD}$ ), psychopathic features ( $\beta=0.49, p<0.001$ for delinquency and $\beta=0.63, p<0.001$ for $\mathrm{CD}$ ), and the interaction between both $(\beta=0.37$, $p<0.001$ for delinquency and $\beta=0.09, p<0.05$ for $\mathrm{CD}$ ) were significantly associated with the outcomes.

Fig. 3 shows model 3. In this model Reactive Overt aggression ( $\beta=$ $0.30, p<0.001$ for delinquency and $\beta=0.40, p<0.001$ for $\mathrm{CD}$ ), psychopathic features $(\beta=0.30, p<0.001$ for delinquency and $\beta=0.47, p$ $<0.001$ for $\mathrm{CD}$ ), and the interaction between both $(\beta=0.41, p<0.001$ for delinquency and $\beta=0.06$, ns for $\mathrm{CD}$ ) were significantly associated

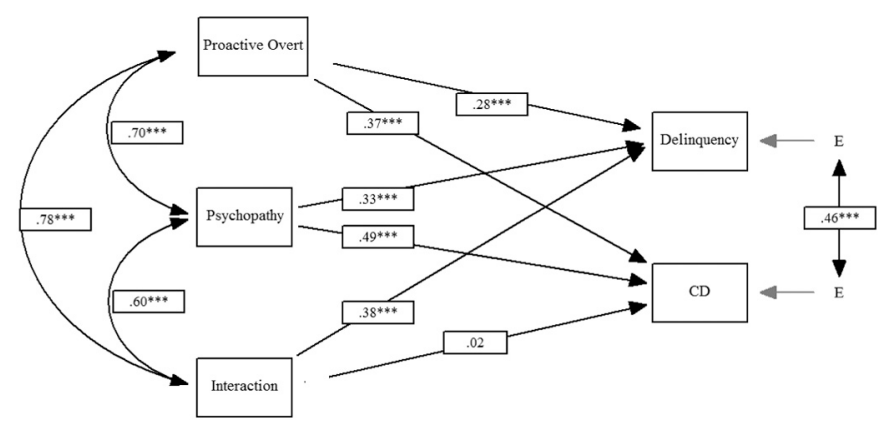

Fig. 1. Effects of proactive overt aggression on delinquency and conduct disorder moderated by psychopathy.

Note. $\mathrm{CD}=$ conduct disorder; ${ }^{* * *} p \leq 0.001$.

Table 1

Pearson correlation matrix and descriptives.

\begin{tabular}{|c|c|c|c|c|c|c|c|}
\hline & Proactive overt & Proactive relational & Reactive overt & Reactive relational & DD psychopathy & AHSRD & CDS \\
\hline Proactive overt & 1 & & & & & & \\
\hline Proactive relational & $0.58^{* k * k}$ & 1 & & & & & \\
\hline Reactive overt & $0.84^{* * *}$ & $0.64^{* * *}$ & 1 & & & & \\
\hline Reactive relational & $0.56^{* * *}$ & $0.62^{* * *}$ & $0.55^{* * *}$ & 1 & & & \\
\hline DD psychopathy & $0.71^{* k *}$ & $0.44^{* k *}$ & $0.64^{* * *}$ & $0.32^{\text {*** }}$ & 1 & & \\
\hline AHSRD & $0.83^{* * *}$ & $0.53^{* * *}$ & $0.75^{* k *}$ & $0.46^{* * * *}$ & $0.77^{* * *}$ & 1 & \\
\hline CDS & $0.74^{* * *}$ & $0.48^{* * *}$ & $0.74^{* * *}$ & $0.39^{* * *}$ & $0.77^{* * *}$ & $0.82^{* * *}$ & 1 \\
\hline$M(S D)$ & $1.42(2.58)$ & $2.30(2.41)$ & $2.79(3.46)$ & $3.29(2.49)$ & $7.60(3.34)$ & $3.30(5.64)$ & $8.88(0.38)$ \\
\hline Skewness & 1.91 & 3.14 & 1.23 & 0.95 & 1.08 & 2.59 & 1.06 \\
\hline Kurtosis & 2.76 & 4.73 & 0.79 & 0.49 & 0.21 & 7.07 & 0.83 \\
\hline
\end{tabular}

Note. $\mathrm{DD}=$ dirty doZEn; AHSRD = Add Health Self-Report Delinquency; CDS $=$ conduct disorder SCREENER; $M(S D)=$ MEAN (STANDARD DEVIATION).

**** $p \leq 0.001$. 


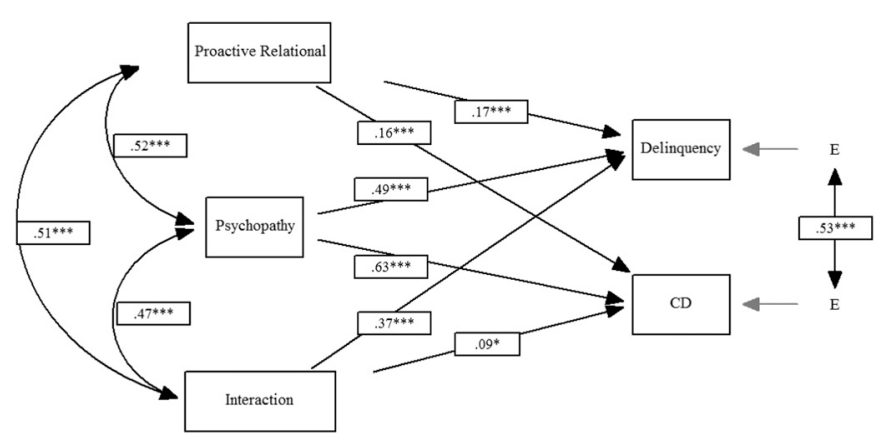

Fig. 2. Effects of proactive relational aggression on delinquency and conduct disorder moderated by psychopathy.

Note. $\mathrm{CD}=$ conduct disorder; ${ }^{*} p \leq 0.05,{ }^{* * *} p \leq 0.001$.

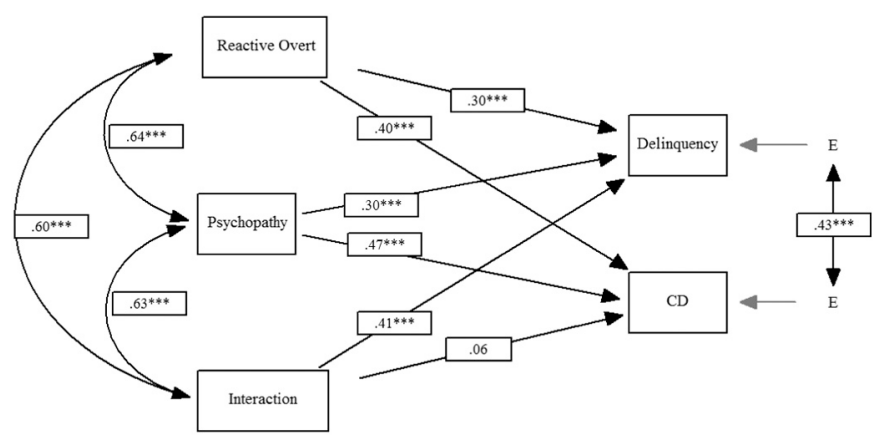

Fig. 3. Effects of reactive overt aggression on delinquency and conduct disorder moderated by psychopathy.

Note. $\mathrm{CD}=$ conduct disorder; $* * * p \leq 0.001$.

with the outcomes, with the exception of the interaction regarding $C D$ which was non-significant.

Finally, Fig. 4 shows model 4. In this model Reactive Relational aggression $(\beta=0.16, p<0.01$ for delinquency and $\beta=0.15, p<0.01$ for $\mathrm{CD})$, psychopathic features $(\beta=0.60, p<0.001$ for delinquency and $\beta=$ $0.69, p<0.001$ for CD), and the interaction between both $(\beta=0.28, p<$ 0.001 for delinquency and $\beta=0.06$, ns for $\mathrm{CD}$ ) were significantly associated with the outcomes, with the exception of the interaction regarding $\mathrm{CD}$ which was non-significant.

\section{Discussion}

The present study examined the hypothesis that psychopathic traits moderate the connection between proactive overt, proactive relational, reactive overt, and reactive relational aggression in predicting delinquency and conduct disorder outcomes. Significant moderation was

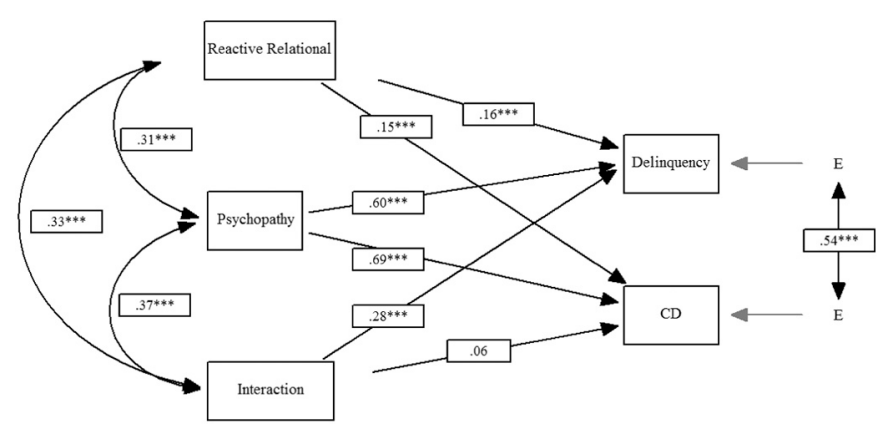

Fig. 4. Effects of reactive relational aggression on delinquency and conduct disorder moderated by psychopathy.

Note. $\mathrm{CD}=$ conduct disorder; ${ }^{* * *} p \leq 0.001$. found for all four models with the delinquency outcome but only in one of four models-for proactive relational aggression-in the conduct disorder outcome thus producing partial support. Four main findings warrant discussion.

First, the models revealed the robustness and generality of the effects of psychopathic features and aggression as these measures were always significantly associated with delinquency and conduct disorder. Within the general population of youth such as our school-based sample, these constructs are important markers of clinical conduct problems. This is consistent with criminological research showing that psychopathic traits are also a powerful driver of more severe, chronic, and violent youth offending trajectories (Baglivio, Wolff, DeLisi, \& Jackowski, 2020; Cale, Lussier, McCuish, \& Corrado, 2015; Corrado, McCuish, Hart, \& DeLisi, 2015; Farina, Holzer, DeLisi, \& Vaughn, 2018; Vaughn, Howard, \& DeLisi, 2008). Thus, in both adjudicated and general population samples of youth, psychopathy and aggression are important risk factors.

Second, given the robustness of psychopathy and aggression, we hypothesized that their interaction would constitute an antisocial alchemy that significantly increases delinquency and conduct problems. This was certainly true for delinquency: youth who are more aggressive and have more pronounced psychopathic features engage in more delinquent acts and this effect occurred for all forms of aggression whether proactive, reactive, overt, or relational. The synergistic effects evidenced by the interaction are consistent with several delinquent career studies (e.g., Baglivio et al., 2020; Cale et al., 2015; Corrado et al., 2015; Vaughn et al., 2008). We were admittedly surprised by the three null associations between the psychopathic features-aggression interaction and Conduct Disorder. Only in the case of proactive relational aggression was there evidence of moderation. We suspect that the brief $C D$ screener measure we employed, that only has 6-items likely is not capturing the full development of a conduct disorder diagnosis or symptoms as shown in prior research (e.g., Foster et al., 2005; Schaeffer, Petras, Ialongo, Poduska, \& Kellam, 2003; Vitaro et al., 1998). Moreover, the current sample also disproportionately contains lower-risk, normative types of delinquents (e.g., Moffitt, 1993; Vaughn, SalasWright, DeLisi, \& Maynard, 2014) whose conduct and psychopathology is unlikely to rise to the level of either clinically remarkable impairment or a clinical diagnosis.

Third, interesting findings emerged using a multidimensional aggression measure like the PCS-20. Within the proactive and reactive domains, the effects for overt aggression were approximately two to three times greater than relational aggression as indicated by $\beta$ coefficients. This makes intuitive sense since overt aggression corresponds more directly to delinquent acts and CD traits. However, the effects for relational aggression are also significant and not trivial with $\beta$ coefficients ranging from 0.15 to 0.17 . We suspect the relational aggression findings are consistent with the peer rejection and social exclusion that may be underway among these youth (Dodge \& Coie, 1987). Highly aggressive youth sooner than later create fatigue among more normatively behaved peers, who after repeated exposure to aggressive acts, simply disengage from their more aggressive peers. However, peer rejection and social exclusion are likely not state dependent experiences, but instead occur in a process manner over time (Coie, Lochman, Terry, \& Hyman, 1992; Kornienko, Ha, \& Dishion, 2020; Laird, Jordan, Dodge, Pettit, \& Bates, 2001). Relational aggression thus reflects socially inappropriate ways for highly aggressive peers to manage social relationships before they close permanently.

Fourth, from an intervention standpoint, we encourage programs that target aggression since it is a normative phenomenon relative to psychopathic features, which is a more challenging condition one with more controversial treatment outcomes (Polaschek, 2019; Rojas \& Olver, 2021; Salekin, 2002). One intervention with some evidence of effectiveness is Aggression Replacement Training that involves a "skill streaming" curriculum where youth are trained in beginning social skills, advanced social skills, skills for dealing with feelings, alternatives to aggression, skills for dealing with stress, and planning skills 
(Goldstein \& Glick, 1994). These basic instructions provide youth with appropriate social skills and behavioral options to reduce aggression as either a response to a perceived problem (e.g., reactive) or as a mechanism to gain social status (e.g., proactive). As the current models shown, disrupting various forms of aggression can help to potentially disrupt the causal chains resulting in delinquency and conduct disorder. $^{3}$

There are important limitations of the current study that future researchers can build upon especially the use of longitudinal data that can specify the temporal ordering of study variables unlike our data where measures were assessed at the same time. In addition to the moderation effects herein, there is ample evidence that various forms of aggression, psychopathy, and externalizing outcomes exhibit multifaceted causal and reciprocal relationships (Byrd, Loeber, \& Pardini, 2012; Kimonis, Centifanti, Allen, \& Frick, 2014; Walters, 2018), thus a longitudinal design is important. We encourage replication of the current study with more severe delinquent samples as well as extension of this research with alternative measures of psychopathy. A limitation of our work is that the school-based community sample contains participants whose conduct is benign relative to youth committed to confinement facilities, for instance (e.g., Bonner, DeLisi, Jones-Johnson, Caudill, \& Trulson, 2020; Trulson, Haerle, Caudill, \& DeLisi, 2016). In an enriched sample of youth where the prevalence of aggression, psychopathy, and conduct problems is much greater, it would be interesting to see if a different antisocial alchemy emerges. Another limitation was we did not control statistically for the potential influence of covariates (e.g., individual, family and community variables) that could add robustness to the path analyses models. The current study is also limited by shared methods variance thus external data sources, such as police contacts or court referrals would be useful to see if the most aggressive and psychopathic also attract the most justice system attention. We suspect so, and encourage additional research on the antisocial alchemy that underscores delinquent development.

\section{References}

American Psychiatric Association. (2013). Diagnostic and statistical manual of mental disorders (fifth edition (DSM-5)). American Psychiatric Publishing.

Anderson, C. A., \& Bushman, B. J. (2002). Human aggression. Annual Review of Psychology, 53(1), 27-51. https://doi.org/10.1146/annurev. psych.53.100901.135231.

Baglivio, M. T., Wolff, K. T., DeLisi, M., \& Jackowski, K. (2020). The role of adverse childhood experiences (ACEs) and psychopathic features on juvenile offending criminal careers to age 18. Youth Violence and Juvenile Justice. https://doi.org/ $10.1177 / 1541204020927075$.

Barker, E. D., Tremblay, R. E., Nagin, D. S., Vitaro, F., \& Lacourse, E. (2006). Development of male proactive and reactive physical aggression during adolescence. Journal of Child Psychology and Psychiatry, 47(8), 783-790. https://doi.org/10.1111/ j.1469-7610.2005.01585.x.

Bentler, P. M., \& Wu, E. J. (2018). EQS 6.4 for Windows. Multivariate Software Inc.

Blunch, N. J. (2016). Introduction to structural equation modeling using IBM SPSS statistics and EQS. SAGE.

Bonner, T., DeLisi, M., Jones-Johnson, G., Caudill, J. W., \& Trulson, C. (2020). Chaotic homes, adverse childhood experiences, and serious delinquency: Differential effects by race and ethnicity. Justice Quarterly, 37(4), 697-714. https://doi.org/10.1080/ 07418825.2019.1688852.

Brännström, L., Kaunitz, C., Andershed, A. K., South, S., \& Smedslund, G. (2016). Aggression replacement training (ART) for reducing antisocial behavior in adolescents and adults: A systematic review. Aggression and Violent Behavior, 27, 30-41. https://doi.org/10.1016/j.avb.2016.02.006.

Byrd, A. L., Loeber, R., \& Pardini, D. A. (2012). Understanding desisting and persisting forms of delinquency: The unique contributions of disruptive behavior disorders and interpersonal callousness. Journal of Child Psychology and Psychiatry, 53(4), 371-380. https://doi.org/10.1111/j.1469-7610.2011.02504.x.

\footnotetext{
${ }^{3}$ A consistent feature of behavioral modification programs relating to antisocial conduct is that program effects are commonly limited to the duration of the program and a brief follow-up evaluation phase. In the long term, treatment effects have small to null effects on behavioral outcomes, such as recidivism among juveniles. Meta-analytic research on Aggression Replacement Training in particular shows that the intervention does not result in lower recidivism (Brännström, Kaunitz, Andershed, South, \& Smedslund, 2016).
}

Cale, J., Lussier, P., McCuish, E., \& Corrado, R. (2015). The prevalence of psychopathic personality disturbances among incarcerated youth: Comparing serious, chronic, violent and sex offenders. Journal of Criminal Justice, 43(4), 337-344. https://doi. org/10.1016/j.jcrimjus.2015.04.005.

Card, N. A., \& Little, T. D. (2006). Proactive and reactive aggression in childhood and adolescence: A meta-analysis of differential relations with psychosocial adjustment. International Journal of Behavioral Development, 30(5), 466-480. https://doi.org/ $10.1177 / 0165025406071904$.

Cima, M., \& Raine, A. (2009). Distinct characteristics of psychopathy relate to different subtypes of aggression. Personality and Individual Differences, 47(8), 835-840. https://doi.org/10.1016/j.paid.2009.06.031.

Coie, J. D., Lochman, J. E., Terry, R., \& Hyman, C. (1992). Predicting early adolescent disorder from childhood aggression and peer rejection. Journal of Consulting and Clinical Psychology, 60(5), 783-792. https://doi.org/10.1037/0022-006X.60.5.783.

Corrado, R. R., McCuish, E. C., Hart, S. D., \& DeLisi, M. (2015). The role of psychopathic traits and developmental risk factors on offending trajectories from early adolescence to adulthood: A prospective study of incarcerated youth. Journal of Criminal Justice, 43(4), 357-368. https://doi.org/10.1016/j.jcrimjus.2015.04.007.

Crick, N. R., \& Dodge, K. A. (1996). Social information-processing mechanisms in reactive and proactive aggression. Child Development, 67(3), 993-1002. https://doi. org/10.1111/j.1467-8624.1996.tb01778.x.

DeLisi, M. (2016). Psychopathy as unified theory of crime. Palgrave Macmillan.

DeLisi, M., \& Vaughn, M. G. (2015). Ingredients for criminality require genes, temperament, and psychopathic personality. Journal of Criminal Justice, 43(4), 290-294, 10./1016/j.jcrimjus.2015.05.005.

Dodge, K. A., \& Coie, J. D. (1987). Social-information-processing factors in reactive and proactive aggression in children's peer groups. Journal of Personality and Social Psychology, 53(6), 1146-1158.

Farina, A. S., Holzer, K. J., DeLisi, M., \& Vaughn, M. G. (2018). Childhood trauma and psychopathic features among juvenile offenders. International Journal of Offender Therapy and Comparative Criminology, 62(14), 4359-4380. https://doi.org/10.1177/ 0306624 X18766491.

Farrington, D. P. (2009). Conduct disorder, aggression, and delinquency. In R. M. Lerner, \& L. Steinberg (Eds.), Handbook of adolescent psychology: Individual bases of adolescent development (pp. 683-722). John Wiley \& Sons Inc.. https://doi.org/10.1002/ 9780470479193.adlpsy001021

Ferguson, C. J. (2009). An effect size primer: A guide for clinicians and researchers. Professional Psychology: Research and Practice, 40(5), 532-538. https://doi.org/ 10.1037/a0015808.

Foster, E. M., Jones, D. E., \& Conduct Problems Prevention Research Group. (2005). The high costs of aggression: Public expenditures resulting from conduct disorder. American Journal of Public Health, 95(10), 1767-1772. https://doi.org/10.2105/ AJPH.2004.061424.

Frick, P. J., Cornell, A. H., Barry, C. T., Bodin, S. D., \& Dane, H. E. (2003). Callousunemotional traits and conduct problems in the prediction of conduct problem severity, aggression, and self-report of delinquency. Journal of Abnormal Child Psychology, 31(4), 457-470. https://doi.org/10.1023/A:1023899703866.

Geerlings, Y., Asscher, J. J., Stams, G. J. J., \& Assink, M. (2020). The association between psychopathy and delinquency in juveniles: A three-level meta-analysis. Aggression and Violent Behavior, 50, 101342. https://doi.org/10.1016/j.avb.2019.101342.

Goldstein, A. P., \& Glick, B. (1994). Aggression replacement training: Curriculum and evaluation. Simulation \& Gaming, 25(1), 9-26. https://doi.org/10.1177/ 1046878194251003.

Hare, R. D. (1996). Psychopathy and antisocial personality disorder: A case of diagnostic confusion. Psychiatric Times, 13(2), 39-40.

Hare, R. D. (1999). Without conscience: The disturbing world of the psychopaths among us. The Guilford Press.

Hare, R. D., Hart, S. D., \& Harpur, T. J. (1991). Psychopathy and the DSM-IV criteria for antisocial personality disorder. Journal of Abnormal Psychology, 100(3), 391-398. https://doi.org/10.1037/0021-843X.100.3.391.

Jonason, P. K., \& Webster, G. D. (2010). The dirty dozen: A concise measure of the dark triad. Psychological Assessment, 22(2), 420-432.

Kerr, M., Van Zalk, M., \& Stattin, H. (2012). Psychopathic traits moderate peer influence on adolescent delinquency. Journal of Child Psychology and Psychiatry, 53(8), 826-835. https://doi.org/10.1111/j.1469-7610.2011.02492.x.

Kimonis, E. R., Centifanti, L. C., Allen, J. L., \& Frick, P. J. (2014). Reciprocal influences between negative life events and callous-unemotional traits. Journal of Abnormal Child Psychology, 42, 1287-1298. https://doi.org/10.1007/s10802-014-9882-9.

Kornienko, O., Ha, T., \& Dishion, T. J. (2020). Dynamic pathways between rejection and antisocial behavior in peer networks: Update and test of confluence model. Development and Psychopathology, 32(1), 175-201.

Laird, R. D., Jordan, K. Y., Dodge, K. A., Pettit, G. S., \& Bates, J. E. (2001). Peer rejection in childhood, involvement with antisocial peers in early adolescence, and the development of externalizing behavior problems. Development and Psychopathology, 13(2), 337-354.

Lau, K. S. L., \& Marsee, M. A. (2013). Exploring narcissism, psychopathy, and Machiavellianism in youth: Examination of associations with antisocial behavior and aggression. Journal of Child and Family Studies, 22, 355-367. https://doi.org/ 10.1007/s10826-012-9586-0.

Lee, Y., \& Kim, J. (2020). Psychopathic traits and different types of criminal behavior: An assessment of direct effects and mediating processes. Journal of Criminal Justice, 101772. https://doi.org/10.1016/j.jcrimjus.2020.101772.

Lewinsohn, P. M., Rohde, P., \& Farrington, D. P. (2000). The OADP-CDS: A brief screener for adolescent conduct disorder. Journal of the American Academy of Child \& Adolescent Psychiatry, 39(7), 888-895. https://doi.org/10.1097/000045832000007000-00018. 
Lorber, M. F. (2004). Psychophysiology of aggression, psychopathy, and conduct problems: A meta-analysis. Psychological Bulletin, 130(4), 531-552. https://doi.org/ 10.1037/0033-2909.130.4.531.

Manders, W. A., Deković, M., Asscher, J. J., van der Laan, P. H., \& Prins, P. J. (2013). Psychopathy as predictor and moderator of multisystemic therapy outcomes among adolescents treated for antisocial behavior. Journal of Abnormal Child Psychology, 41 (7), 1121-1132. https://doi.org/10.1007/s10802-013-9749-5.

Maroco, J. (2014). Análise de equações estruturais: Fundamentos teóricos, software \& aplicações [Analysis of structural equations: Theoretical foundations, software, and applications]. Lisbon, Portugal: Report Number.

Marsee, M. A., \& Frick, P. J. (2007). Exploring the cognitive and emotional correlates to proactive and reactive aggression in a sample of detained girls. Journal of Abnormal Child Psychology, 35(6), 969-981. https://doi.org/10.1007/s10802-007-9147-y.

Marsee, M. A., Silverthorn, P., \& Frick, P. J. (2005). The association of psychopathic traits with aggression and delinquency in non-referred boys and girls. Behavioral Sciences \& the Law, 23(6), 803-817. https://doi.org/10.1002/bsl.662.

Marsee, M. A., Barry, C. T., Childs, K. K., Frick, P. J., Kimonis, E. R., Muñoz, L. C., .. Lau, K. S. L. (2011). Assessing the forms and functions of aggression using selfreport: Factor structure and invariance of the Peer Conflict Scale in youths. Psychological Assessment, 23(3), 792-804. https://doi.org/10.1037/a0023369.

Moffitt, T. E. (1993). Adolescence-limited and life-course-persistent antisocial behavior: A developmental taxonomy. Psychological Review, 100(4), 674. https://doi.org/ 10.1037/0033-295X.100.4.674.

Muñoz, L. C., Frick, P. J., Kimonis, E. R., \& Aucoin, K. J. (2008). Verbal ability and delinquency: Testing the moderating role of psychopathic traits. Journal of Child Psychology and Psychiatry, 49(4), 414-421. https://doi.org/10.1111/j.14697610.2007.01847.x.

Ogloff, J. R. (2006). Psychopathy/antisocial personality disorder conundrum. The Australian and New Zealand Journal of Psychiatry, 40(6-7), 519-528. https://doi.org/ 10.1080/j.1440-1614.2006.01834.x.

Orue, I., Calvete, E., \& Gamez-Guadix, M. (2016). Gender moderates the association between psychopathic traits and aggressive behavior in adolescents. Personality and Individual Differences, 94, 266-271. https://doi.org/10.1016/j.paid.2016.01.043.

Palma, V. H., Pechorro, P., Jesus, S. N., \& Nunes, C. (2021) Psychometric properties of the Conduct Disorder Screener among Portuguese youths. Manuscript under review.

Pechorro, P., Russell, J. D., Ayala-Nunes, L., Gonçalves, R. A., \& Nunes, C. (2018). The Brief Peer Conflict Scale: Psychometric properties among a sample of incarcerated male juvenile offenders. International Journal of Offender Therapy and Comparative Criminology, 62(8), 2414-2429. https://doi.org/10.1177/0306624x17719299.

Pechorro, P., DeLisi, M., Gonçalves, R. A., Quintas, J., \& Palma, V. (2019a). The brief psychopathy scale and its refined version among incarcerated and community youths: Psychometrics and measurement invariance. Deviant Behavior. https://doi. org/10.1080/01639625.2019.1684942.

Pechorro, P., Jonason, P. K., Raposo, V., \& Maroco, J. (2019). Dirty dozen: A concise measure of dark triad traits among at-risk youths. Current Psychology, 1-10.

Pechorro, P., Moreira, K., Basto-Pereira, M., Oliveira, J. P., \& Ray, J. V. (2019b). The selfreport delinquency scale from the National Longitudinal Study of Adolescent to Adult Health among at-risk for delinquency youths. Violence and Victims, 34(1), 120-135. https://doi.org/10.1891/0886-6708.VV-D-17-00165.

Pechorro, P., Hayes, N., Gonçalves, M., Palma, V. H., Gonçalves, R. A., \& Marsee, M. (2020). Portuguese validation of the Brief Peer Conflict Scale: Validity, reliability and invariance across gender. Journal of Psychopathology and Behavioral Assessment. https://doi.org/10.1007/s10862-020-09826-31-11.

Polaschek, D. (2019). The treatment of psychopathy. In M. DeLisi (Ed.), Routledge international handbook of psychopathy and crime (pp. 610-634). Routledge.

Polman, H., de Castro, B. O., Koops, W., van Boxtel, H. W., \& Merk, W. W. (2007). A meta-analysis of the distinction between reactive and proactive aggression in children and adolescents. Journal of Abnormal Child Psychology, 35(4), 522-535. https://doi.org/10.1007/s10802-007-9109-4.

Raine, A., Dodge, K., Loeber, R., Gatzke-Kopp, L., Lynam, D., Reynolds, C., ... Liu, J. (2006). The reactive-proactive aggression questionnaire: Differential correlates of reactive and proactive aggression in adolescent boys. Aggressive Behavior, 32(2), 159-171. https://doi.org/10.1002/ab.20115.

Rojas, E. Y., \& Olver, M. E. (2021). Juvenile psychopathy and community treatment response in youth adjudicated for sexual offenses. International Journal of Offender Therapy and Comparative Criminology. https://doi.org/10.1177/0306624X21994066.

Salekin, R. T. (2002). Psychopathy and therapeutic pessimism: Clinical lore or clinical reality? Clinical Psychology Review, 22(1), 79-112. https://doi.org/10.1016/S02727358(01)00083-6.

Schaeffer, C. M., Petras, H., Ialongo, N., Poduska, J., \& Kellam, S. (2003). Modeling growth in boys' aggressive behavior across elementary school: Links to later criminal involvement, conduct disorder, and antisocial personality disorder. Developmental Psychology, 39(6), 1020-1035. https://doi.org/10.1037/0012- 1649.39.6.1020.

Shipley, S., \& Arrigo, B. A. (2001). The confusion over psychopathy (II): Implications for forensic (correctional) practice. International Journal of Offender Therapy and Comparative Criminology, 45(4), 407-420. https://doi.org/10.1177/ 0306624 X01454002.

Trulson, C. R., Haerle, D. R., Caudill, J. W., \& DeLisi, M. (2016). Lost causes: Blended sentencing, second chances, and the Texas youth commission. University of Texas Press.

Vaughn, M. G., Howard, M. O., \& DeLisi, M. (2008). Psychopathic personality traits and delinquent careers: An empirical examination. International Journal of Law and Psychiatry, 31(5), 407-416. https://doi.org/10.1016/j.ijlp.2008.08.001.

Vaughn, M. G., Salas-Wright, C. P., DeLisi, M., \& Maynard, B. R. (2014). Violence and externalizing behavior among youth in the United States: Is there a severe 5\%? Youth Violence and Juvenile Justice, 12(1), 3-21. https://doi.org/10.1177/ 1541204013478973.

Vitaro, F., Gendreau, P. L., Tremblay, R. E., \& Oligny, P. (1998). Reactive and proactive aggression differentially predict later conduct problems. Journal of Child Psychology and Psychiatry, 39(3), 377-385. https://doi.org/10.1111/1469- 7610.00333.

Walters, G. D. (2018). Exposure to violence as a mediator of the CU-aggression relationship: On the importance of establishing the causal direction of variables in a path analysis. Journal of Psychopathology and Behavioral Assessment, 40(2), 169-179.

Yeh, M. T., Chen, P., Raine, A., Baker, L. A., \& Jacobson, K. C. (2011). Child psychopathic traits moderate relationships between parental affect and child aggression. Journal of the American Academy of Child \& Adolescent Psychiatry, 50(10), 1054-1064. https:// doi.org/10.1016/j.jaac.2011.06.013.

Yoon, D., Eher, R., \& Mokros, A. (2021). Incremental validity of the Psychopathy Checklist-Revised above and beyond the diagnosis of antisocial personality disorder regarding recidivism in sexual offenders. Journal of Criminal Justice, 101780. https:// doi.org/10.1016/j.jcrimjus.2020.101780. 